\title{
Critérios técnicos para a seleção de pulverizadores autopropelidos comercializados no mercado brasileiro
}

\author{
Technical criteria for the selection of self-propelled sprayers available in the Brazilian market
}

\author{
Marcelo Silveira de Farias $^{\mathrm{I}^{*}}$ José Fernando Schlosser ${ }^{\mathrm{II}}$ \\ Javier Solis Estrada ${ }^{I}$ Alfran Tellechea Martini ${ }^{I}$ Juan Paulo Barbieri ${ }^{I I I}$
}

\section{- NOTA -}

\section{RESUMO}

Nos últimos anos, a oferta de pulverizadores autopropelidos no mercado brasileiro aumentou, principalmente para suprir a demanda de agricultores que possuem grandes extensões de áreas, nas quais se requer um alto ritmo operacional. Neste trabalho, foram avaliados, em função da potência nominal do motor, os diferentes tipos de transmissões, a capacidade do reservatório de calda, tamanho das barras e vão livre, considerados critérios técnicos importantes para a seleção dessas máquinas. Para tanto, utilizaram-se informações técnicas de 41 modelos de pulverizadores autopropelidos comercializados no mercado brasileiro. Como resultado, classificaram-se os pulverizadores em cinco classes, segundo a potência do motor. Verificou-se que, com o aumento da potência, os pulverizadores são equipados com transmissão hidrostática e a capacidade dos reservatórios de calda são maiores.

Palavras-chave: pulverizadores hidráulicos, faixas de potência, classificação.

\section{ABSTRACT}

In recent years the offer of self-propelled sprayers in the Brazilian market increased mainly to supply the demand of farmers who own large areas where there are a high operational pace requirement. In this research the different kinds of transmissions, tank capacity of spray mix, width of bars and clearance, which are considered important technical criteria, were evaluated according to nominal engine power. Technical information of 41 selfpropelled sprayer models commercialized in Brazilian market were used. As result, sprayers were classified in five classes, according to the engine power. It was verified that, with the increase of power, the sprayers are equipped with hydrostatic transmission and the tank capacity of spray mix are higher.

Key words: hydraulic sprayers, power ranges, classification.
Os pulverizadores são utilizados para aplicar agrotóxicos e fazer com que estes produtos atinjam o alvo desejado. No mercado brasileiro, existem diversos tipos, desde os mais simples, do tipo costal, utilizados para atender pequenas áreas, até os pulverizadores autopropelidos, os quais possuem alta tecnologia e elevada capacidade operacional, capazes de atender grandes áreas com qualidade na pulverização (CASALI et al., 2011).

A escolha da máquina e sua correta utilização são fatores fundamentais para se obter qualidade na aplicação e eficiência dos agrotóxicos. Para se obter qualidade nas aplicações, deve-se possuir o maior conhecimento sobre quatro fatores: máquina agrícola, alvo biológico, fatores climáticos e agrotóxicos (SCHLOSSER, 2002).

O motor e a transmissão tornam os pulverizadores autopropelidos autônomos na sua operação. Para o deslocamento da máquina e o acionamento de mecanismos internos do circuito hidráulico, utiliza-se a potência do motor, declarada pelos fabricantes e conhecida como potência nominal, conforme a norma ABNT NBR ISO 3046/1 (1995).

Muitos fatores associados com os pulverizadores tratorizados determinam a eficiência operacional do trabalho, destacando-se: velocidade, tamanho da barra, tempo de manobra, capacidade do reservatório de calda, tempo de reabastecimento edistância percorrida (MATUO, 1990). Além desses, perfeitamente aplicáveis aos pulverizadores autopropelidos, o sistema

\footnotetext{
'Programa de Pós-graduação em Engenharia Agrícola (PPGEA), Universidade Federal de Santa Maria (UFSM), 97105-900, Santa Maria, RS, Brasil. Email: silveira_farias@hotmail.com.*Autor para correspondência.

IIDepartamento de Engenharia Rural (DER), Centro de Ciências Rurais (CCR), UFSM, Santa Maria, RS, Brasil.

${ }^{\text {IIIC }}$ urso de Agronomia, UFSM, Santa Maria, RS, Brasil. 
de transmissão de potência também é responsável pelo desempenho e eficiência a campo.

Com isso, o objetivo do trabalho foi avaliar os tipos de transmissões, a capacidade do reservatório de calda, tamanho das barras e vão livre, em função da potência nominal do motor, em 41 modelos de pulverizadores autopropelidos comercializados no Brasil.

Os pulverizadores foram classificados quanto à seguinte faixa de potência proposta: Classe I (menor ou igual a $80 \mathrm{~kW}$ ); Classe II (maior que 80 até $110 \mathrm{~kW}$ ); Classe III (maior que 110 até $140 \mathrm{~kW}$ ); Classe IV (maior que140 até $170 \mathrm{~kW}$ ) e Classe V (maior que $170 \mathrm{~kW}$ ). As transmissões foram classificadas em mecânicas e hidrostáticas; a capacidade do reservatório de calda foi analisada em termos de volume com faixas, menor ou igual a $2.000 \mathrm{~L}$; entre 2.000 e $3.000 \mathrm{~L}$; e igual ou maior que 3.000L. O tamanho das barras, pelo seu comprimento em menor ou igual a $21 \mathrm{~m}$; entre 21 e $25 \mathrm{~m}$ e igual ou maior que $25 \mathrm{~m}$. O vão livre foi analisado segundo os valores médios para cada classe de potência.

Como resultado, não foram encontrados pulverizadores autopropelidos pertencentes à Classe I. A figura 1 (A) demonstra que, quanto à potência, $34 \%$ representam a Classe II, $29 \%$ a Classe III, $27 \%$ a Classe IV e $10 \%$ a Classe V. Estes valores podem ser explicadospelafatiademercado, aqualpretendeatender cada fabricante ou importador de pulverizadores. Ao analisar a figura 1 (B), referente à distribuição dos modelos por faixa de potência nominal, pode-se diferenciar dois grupos: motores com quatro e seis cilindros. Os motores dos pulverizadores das classes III, IV e V possuem seis cilindros, justificando o alcance de maior potência do motor. Apenas um modelo da Classe II possui motor com seis cilindros, o qual fornece $88,3 \mathrm{~kW}$ de potência.

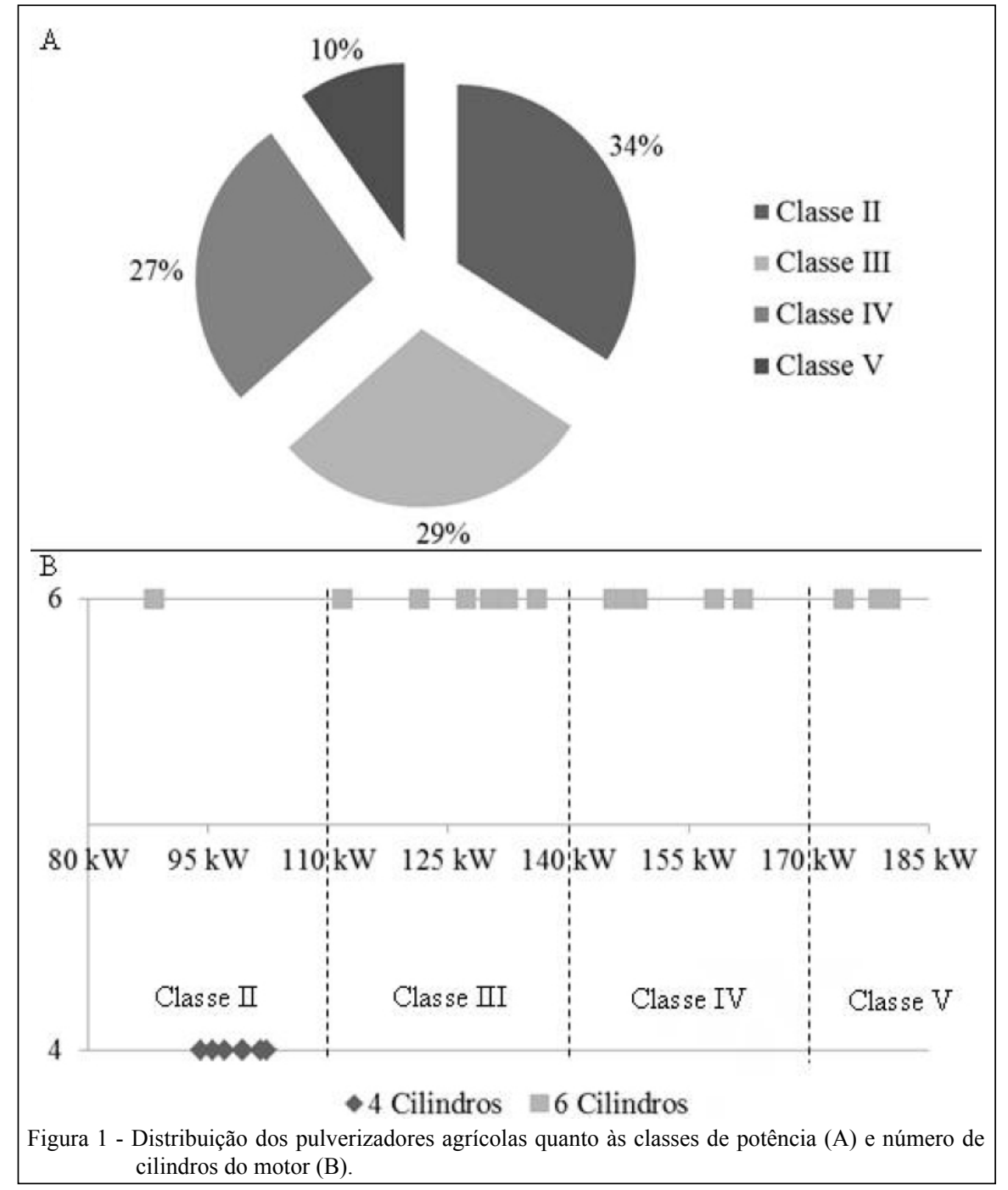

Ciência Rural, v.45, n.5, mai, 2015. 
Pode-se observar que os pulverizadores com motores de quatro cilindros atingem uma potência nominal de $102,2 \mathrm{~kW}$, diferentemente do que se encontra ao analisar os motores dos tratores agrícolas, em que, segundo levantamento realizado por FARIAS (2014), motores de quatro cilindros alcançam até $88,3 \mathrm{~kW}$.

No que se refere ao sistema de transmissão, a informação apresentada na figura 2 (A) permite observar que, para pulverizadores pertencentes às Classes II e III, a transmissão mecânica equipa 57,1\% e $41,7 \%$ das máquinas, respectivamente. A partir da Classe IV, todos os pulverizadores oferecidos no mercado nacional são equipados com transmissões hidrostáticas. Resultado semelhante foi encontrado por RIBAS et al. (2010), no qual todos os tratores agrícolas com motores acima de $147 \mathrm{~kW}$ de potência apresentam

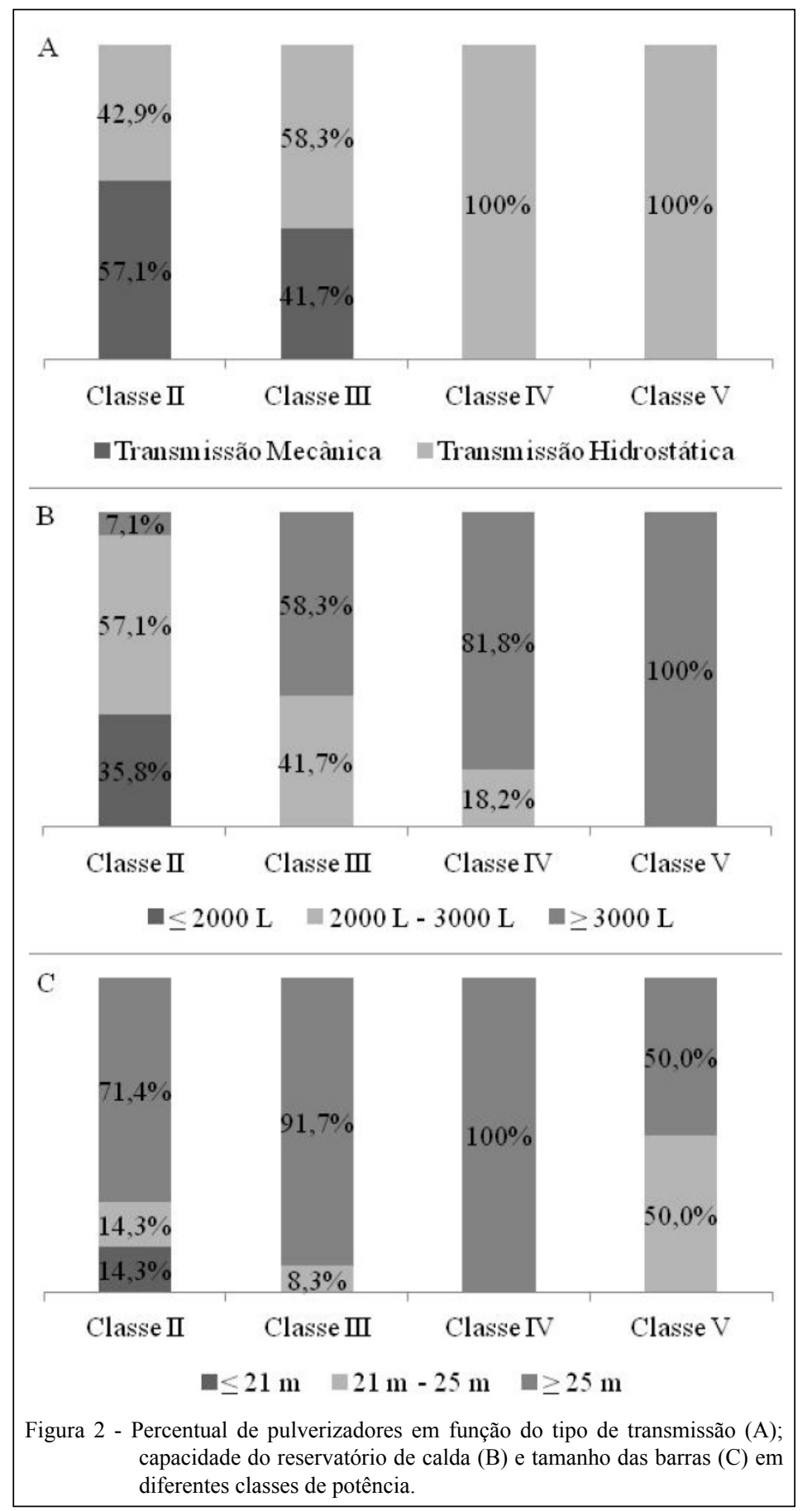

Ciência Rural, v.45, n.5, mai, 2015. 
transmissão hidrostática. Este tipo de transmissão proporciona maiores velocidades de deslocamento e operação, manutenção simples e independência entre componentes, como eixos e chassi.

Ao observar a figura 2 (B), constata-se que 92,9\% dos pulverizadores autopropelidos da Classe II possuem capacidade do reservatório de calda de até 3.000 litros, sendo que, 57,1\% dos modelos desta classe são equipados com reservatórios entre 2.000 e 3.000 litros, e 35,8\% possuem reservatórios de até 2.000 litros. As máquinas das classes III, IV e $\mathrm{V}$ possuem reservatórios com capacidades maiores que 2.000 litros. Percebe-se também que, conforme aumenta a potência nominal do motor, a capacidade dos reservatórios de calda são maiores, sendo igual ou maior que 3.000 litros para todos os pulverizadores da Classe V. Essa tendência ocorre devido à busca por máquinas capazes de alcançar maiores capacidades operacionais. Uma das formas de elevar esse parâmetro é com o aumento da capacidade do reservatório de calda, pois esta maior capacidade reduz a necessidade de paradas para reabastecimentos de calda ou água, dependendo do caso.

Para o parâmetro tamanho das barras, os modelos pertencentes à Classe II estão distribuídos dentro das três categorias de tamanho, em que 14,3; 14,3 e $71,4 \%$ das máquinas são equipadas com barras de largura menor ou igual a $21 \mathrm{~m}$, entre 21 e $25 \mathrm{~m}$ e igual ou maior que $25 \mathrm{~m}$, respectivamente (Figura 2C). Na Classe III, 91,7\% dos pulverizadores possuem barras maiores que $25 \mathrm{~m}$ de largura. Todos os pulverizadores da Classe IV são equipados com barras maiores que $25 \mathrm{~m}$ de largura. Ao contrário do que foi verificado para a capacidade do reservatório de calda, não foi encontrado na Classe $\mathrm{V}$ uma relação direta entre potência nominal do motor e tamanho das barras. Isso pode ser explicado pelo fato de o chassi e sistema de amortecimento das máquinas não suportarem larguras maiores, dificultando a estabilidade e o nivelamento das barras.

Os valores médios de vão livre e coeficientes de variação encontrados foram 1551,4 $\mathrm{mm}(10,1 \%) ; 1571,7 \mathrm{~mm}(17,6 \%) ; 1565,5 \mathrm{~mm}(8,8 \%)$ e $1480,0 \mathrm{~mm}(15,1 \%)$ para as Classes II; III, IV e V, respectivamente. Percebe-se que os pulverizadores de maior potência nominal possuem a menor média de vão livre. Essas máquinas oferecem melhor estabilidade, possibilitando maiores velocidades de operação, visto que o centro de gravidade é menor, tornando a operação mais segura.

Os pulverizadores autopropelidos ofertados no mercado brasileiro podem ser distribuídos em classes, de acordo com a potência nominal do motor. A partir dessa classificação, é possível estabelecer relações com o tipo de transmissão, capacidade do reservatório de calda, tamanho das barras e vão livre. Ao analisar os critérios técnicos anteriormente descritos, percebe-se que, com o aumento da potência, os pulverizadores são equipados com transmissão hidrostática e com maiores reservatórios de calda.

\section{AGRADECIMETOS}

Os autores agradecem ao apoio financeiro da Coordenação de Aperfeiçoamento de Pessoal de Nível Superior (CAPES) e Conselho Nacional de Desenvolvimento Científico e Tecnológico $(\mathrm{CNPq})$ por bolsas de pós-graduação e pela bolsa de produtividade em pesquisa $(\mathrm{CNPq})$ do segundo autor.

\section{REFERÊNCIAS}

ASSOCIAÇÃO BRASILEIRA DE NORMAS TÉCNICAS (ABNT). NBR ISO 3046/1: Motores de combustão interna alternativos - Desempenho - Parte 1: Condições-padrão de referência e declarações de potência e consumos de combustível e óleo lubrificante. Rio de Janeiro, 1995. 15p.

CASALI, A.L. Condições de uso de pulverizadores e tratores na região Central do Rio Grande do Sul. 2012. 109f. Dissertação (Mestrado em Engenharia Agrícola) - Curso de Pós-graduação em Engenharia Agrícola, Universidade Federal de Santa Maria, RS.

FARIAS, M.S. Avaliação de motores de tratores agrícolas utilizando dinamômetro móvel. 2014. 162f. Dissertação (Mestrado em Engenharia Agrícola) - Curso de Pós-graduação em Engenharia Agrícola, Universidade Federal de Santa Maria, RS.

MATUO, T. Técnicas de aplicação de defensivos agrícolas. Jaboticabal: FUNEP, 1990. 139p.

RIBAS, R.L. et al. Transmissões presentes em tratores agrícolas no Brasil. Ciência Rural, Santa Maria, v.40, n.10, p.22062209, 2010. Disponível em: <http://dx.doi.org/10.1590/S0103$84782010005000162>$. Acesso em: 10 fev. 2014. doi: 10.1590/ S0103-84782010005000162.

SCHLOSSER, J.F. Tecnologia de aplicação e uso de máquinas: uso de agroquímicos. Santa Maria: Departamento de Engenharia Rural, 2002. 51p. (Caderno didático, 5). 